$$
\begin{array}{r}
\text { CONVERSAÇÕES EN] } \\
\text { ARTES E CIẼNCIAS SOC } \\
\text { NOS LIM } \\
\text { DO CONTEMPORÂ }
\end{array}
$$




\section{CONVERSAÇÕES ENTRE ARTES E CIÊNCIAS SOCIAIS NOS LIMITES DO CONTEMPORÂNEO}

\section{JOH N FLETCHER}

UNIVERSIDADE FEDERAL DO PARÁ, BELÉM/PA, BRASIL

$$
\text { A GENOR SARRAF }
$$

UNIVERSIDADE FEDERAL DO PARÁ, BELÉM/PA, BRASIL

$$
\text { ERNANI CHAVES }
$$

UNIVERSIDADE FEDERAL DO PARÁ, BELÉM/PA, BRASIL 


\title{
CONVERSAÇÕES ENTRE ARTES E CIÊNCIAS SOCIAIS NOS LI- MITES DO CONTEMPORÂNEO
}

\section{Resumo}

Este estudo visa analisar diálogos recentes e, muitas vezes, divergentes entre as artes visuais e as ciências sociais, de maneira a ajudar na compreensão de nosso presente conflituoso e polifônico. Os diálogos em questão problematizam operações estéticas de sociedades complexas, bem como encaram diferentes experiências como parte de um conjunto de histórias interligadas e sobrepostas, cada uma das quais com seu próprio programa e ritmo de desenvolvimento, todos coexistindo e interagindo entre si. Com o intuito de traçar, longe de um colecionismo de materiais heterogêneos, uma descrição analítica e reflexão interpretativa, o presente trabalho busca encadeamentos teóricos a partir de intelectuais da filosofia e sociologia Pós-Modernas, da antropologia Pós-Moderna do seminário de Santa Fé e das premissas Pós-Colonial e Descolonial. Com um aporte de autores como Fredric Jameson, Jean Baudrillard, James Clifford, Homi Babha, Edward Said, Walter Mignolo, Adolfo Alban, Joaquín Barriendos, entre outros, visamos reiterar, portanto, uma agenda interpretativa destituída dos processos de colonização do poder, do ser, do ouvir, do fazer e do ver para se pensar artes visuais em sociedades periféricas globais.

Palavras-Chave: Arte, cultura, regimes visuais, etnografia do pensamento.

\section{CONVERSATIONS BETWEEN ARTS AND SOCIAL SCIENCES IN THE LIMITS OF THE CONTEMPORARY}

\begin{abstract}
This study aims to analyze recent and, sometimes, divergent dialogues between visual arts and social sciences, moving towards the comprehension of our conflictual and polyphonic present. These dialogues problematize aesthetic operations in complex societies, as well as face different experiences as part of a set of interconnected and juxtaposed stories, each one of them with their own program and rhythm of development, all of them coexisting and interacting with each other. With the objective is to delineate, not a collection of heterogeneous materials, but an analytical description and an interpretive reflection, the present work seeks theoretical chains related to intellectuals from the Postmodern philosophy and sociology, from the Postmodern anthropology of the Santa Fé Seminar and from the Postcolonial and Decolonial premises. With
\end{abstract}


the contribution of authors such as Fredric Jameson, Jean Baudrillard, James Clifford, Homi Babha, Edward Said, Walter Mignolo, Adolfo Alban, Joaquín Barriendos, among others, we seek to reiterate, in this sense, an interpretive agenda devoided of the colonization processes of power, being, listening, doing and seeing to see and think about visual arts in global peripheral societies.

Keywords: Art, culture, visual regimes, ethnography of thought.

\section{CONVERSACIONES ENTRE ARTES Y CIENCIAS SOCIALES EN LOS LIMITES DEL CONTEMPORÁNEO}

\section{Resumen}

Este estudio tiene como objetivo analizar los diálogos recientes y a menudo divergentes entre las artes visuales y las ciencias sociales, con el fin de ayudar en la comprensión de nuestro presente conflictivo y polifónico. Estos diálogos problematizan las operaciones estéticas de las sociedades complejas y miran diferentes experiencias como parte de un conjunto de historias interconectadas y superpuestas, cada una de las cuales con su propio programa y ritmo de desarrollo, todos conviviendo e interactuando entre sí. Para dibujar, lejos de un acaparamiento de materiales heterogéneos, una descripción analítica y reflexión interpretativa, este trabajo busca hilos teóricos desde los intelectuales de filosofía y sociología Posmoderna, de antropología Posmoderna del seminario de Santa Fe y de los supuestos Postcoloniales y Decolonialies. Con un aporte de autores como Fredric Jameson, Jean Baudrillard, James Clifford, Homi babha, Edward Said, Walter Mignolo, Adolfo Albán, Joaquín Barriendos, entre otros, nuestro objetivo es reiterar, por lo tanto, una agenda interpretativa carente del proceso de colonización del poder, del ser, del escuchar, del hacer y del ver para pensar artes visuales en las sociedades periféricas globales.

Palabras Clave: Arte, cultura, sistemas visuales, etnografía del pensamiento.

Endereço do primeiro autor para correspondência: Av. Governador José Malcher, 2480, 401. São Brás, Belém, PA. CEP: 66090-100. 


\section{CONSIDERAÇÕES INICIAIS}

O que convencionamos chamar de contemporâneo ${ }^{1}$, acreditamos, tem possibilitado frentes para se problematizar antigas fronteiras de entendimento. Para além de algumas dessas categorias em processos de luta e de desmantelamento - caso de muitas das separações binaristas, reducionistas e pertencentes ao paradigma Moderno para a lógica social dos estar-junto -, nos chama a atenção como o universo das artes visuais, eixo cultural cambiante entre a objetividade e a subjetividade de sujeitos culturalmente diversos, desempenha um papel persistente para se compreender horizontes dinâmicos, talvez mais inclusivos e menos autoritários (Sarlo 2000).

Conforme detectado por Geertz (2008a), a esfera que compõe as artes não se diferencia em complexidade dos seus referentes sociais. Também caracterizadas, em suas formulações polifônicas ${ }^{2}$, descontínuas e assimétricas por linguagens, estruturas, sistemas, atos, símbolos, padrões de sentimento, as artes, desde o século XVIII, foram apropriadas pelo pensamento imperial e transformadas em uma limitação conceitual e ocidental do que seriam e se antes foram sedimentadas no sublime e no belo, atualmente parecem se revelar vinculadas, de acordo com muitos autores pós-modernos, mais a um vazio autorreferencial para sua autorrecreação (Hall 2009; Mignolo 2010).

"El nuevo mundo se iria conformando sobre la base de la imposición de la visión, normas y costumbres del viejo mundo. Las imágenes de la iglesia católica que fueron fundamentales en el processo de conquista, llegaron primero con la cruz portada por los missioneiros-soldados, luego por todas las obras de arte importadas y las que se realizaron en tierras americanas, no con outro objetivo que el control cultural y mental de los individuos que debían ser evangelizados a cualquier precio para ser redimidos. La colônia, como momento de consolidación del imperio español y portugues en América marcaria una huella indeble desde el sistema administrativo, pero también permeando todo el sistema simbólico de quienes con otras lógicas coexistían en la complejidad sócio-cultural que se iba configurando: indígenas y negros" (Albán 2007: 3).

Com o intuito de problematizar experiências visuais feitas a partir de relações contextuais distintas e que não poderiam ser encerradas somente de acordo com protocolos do centro, a presente pesquisa visa estabelecer diálogos, muitas vezes divergentes, mas produtivos para se abordar sociedades complexas nas periferias globais com a filosofia e a sociologia Pós-Modernas, com a antropologia Pós-Moderna do seminário de Santa Fé e com as premissas Pós-Colonial ${ }^{3}$ e Decolonial ${ }^{4}$.

Para além de ilustrar como o pensamento não é invariável e precisa ser tratado na forma de um projeto de descrição analítica e reflexão interpretativa, capaz de tornar uma rede de entendimentos sociais em fragmentos os quais ora se reforçam mutuamente, ora modificam nossos olhares sobre o futuro (Geertz 2008b), este texto também visa destacar lugares das artes em algumas das 
compreensões das ciências humanas contemporâneas, de maneira a tangenciar a premissa de Edward Said (1994) de pensamento em contraponto, ou seja, um pensamento o qual encara diferentes experiências como parte de um conjunto de histórias interligadas e sobrepostas, cada uma das quais com seu próprio programa e ritmo de desenvolvimento, com suas próprias formações e coerência internas e o seu sistema de relações externas, todos coexistindo e interagindo entre si.

Como bem observou Bhabha (2012), as produções artísticas hoje não devem ser compreendidas se abdicadas de seus tempos e lugares contextuais, mesmo sob a égide intercultural já tão referendada atualmente. Trata-se, para além de traçar interpretações visuais singulares de sociedades diferentes, de um entendimento o qual fornece dimensões autocríticas para as dimensões ainda não experimentadas, as reprocessadas e as que se colocam em um lugar de compartilhamento constituinte com seu público fruidor (Bhabha 2003; 2012).

\section{CONVERSA 1 : A FILOSOFIA E A SO- CIOLOGIA PÓS-MODERNAS NOS REGIMES VISUAIS}

Alguns ecos das primeiras rupturas teórico-sociais em torno das noções de cultura e artes visuais podem ser encontrados no período que veio após o término da Segunda Guerra Mundial e a consequente falência de parte, pelo menos, do chamado plano Moderno ${ }^{5}$ ou Iluminista. Neste período, de certa forma, é pertinente destacar o papel atribuído a Clifford Geertz e aos inte- lectuais tributários das problemáticas trazidas pelos trabalhos deste antropólogo em questão. Esta virada antropológica estabelecida pelo autor, devemos acrescentar, possibilitou inúmeras das fraturas teóricas de parte das anteriores concepções das ciências humanas, com uma série de filiações, dissensões e contra respostas, características de um presente heterogêneo, plurivocal e pretensamente mais integrado (Caldeira 1988; Fletcher et al. 2014).

O antropólogo americano, mesmo passível às inúmeras críticas advindas da antropologia que o seguiu, assim como daquelas ligadas a outros campos do conhecimento, refletiu a transformação de um período contextual, transformado e transformador. $\mathrm{O}$ mundo de então, em torno da década de 1950/1960, vivia os efeitos avassaladores do declínio da narrativa tradicional - uma forma de entendimento refletida por Benjamin (2011a), quando antecipou o aparecimento de uma transmissão fragmentária ante os eventos do holocausto e da Shoat-, de maneira que Geertz, assim como inúmeros de seus contemporâneos e mesmo sucessores, foi inspirador para buscar novas formas de agir sobre o presente e revelar outras lógicas científicas e histórias, postas anteriormente no subterrâneo (Gagnebin 2001; Seligmann-Silva 2006).

As reinscrições teóricas de Clifford Geertz trouxeram perspectivas de enxergar culturas e mundo como fenômenos questionáveis e estranháveis. Foram suas propostas interpretativas as que delinearam e anteciparam algumas das crises do que ficou conhecido 
por condição Pós-Moderna - condição "no interior e entre algumas disciplinas acadêmicas e áreas culturais, na filosofia, na sociologia, na arquitetura, nos estudos sobre o cinema e em assuntos literários" (Connor 2004: 13) - e se aliaram, mesmo discretamente, às teorias feministas e às culturais do grupo de Birmingham para nos fazer ver e reagir contra os cânones da cultura masculina, branca e europeia (Kellner 2001).

No que concerne a esta implosão de paradigmas tradicionais sob a alcunha de Pós-Modernismo, tornaram-se referenciais as publicações de $L a$ Condition Postmoderne, de Jean François Lyotard, em 1979; de Postmodernism: or the Cultural Logic of Late Capitalism, de Fredric Jameson, em 1984; e dos discursos promovidos por Jean Baudrillard, a partir da segunda metade dos anos 1970, uma vez que tais reflexões cooptaram para reinserir e problematizar uma consciência mais inclusiva, indeterminante e vestigial como a que melhor daria conta de analisar e buscar um entendimento crítico dessa nova lógica social e artística global.

Dentre estes autores, Fredric Jameson, de Postmodernism: or the Cultural Logic of Late Capitalism, versão posterior e ampliada do debate já iniciado em Postmodernism and Consumer Society é um dos que nos ajuda, logo de início, a entender este novo regime. Muito aproximado de algumas das inscrições de Jean-François Lyotard (2009), o teórico aqui em questão nos é destacável por ser considerado um relator dos aspectos formais-estilísticos do que foi por ele tido como este novo horizonte so- cial, bem como intérprete de uma nova agenda artística para as sociedades urbanas e ocidentais.

Ao analisar a correlação entre a emergência de novas características formais na cultura com a de um novo tipo de vida social e de uma ordem econômica, Jameson (2007) identificou o fim de uma determinada estrutura de lógica cultural, ou a derrocada do que ficou estabelecido como a metafísica Moderna (o sublime, em uma concepção hegeliana; a dissolução artística de atingir o absoluto, o estrutural, o explicável e comensurável dentro de assertivas lógicas e captáveis), e viu o mundo mais relacionado à sua dimensão visual. Foi a respeito de como esta simbiose imagética passou a ganhar importância notável na vida do homem, por conseguinte, que o autor pôs-se a repensar os novos tempos como o retorno do belo e do decorativo no lugar do antigo sublime, o abandono da arte e da procura pelo absoluto e pela verdade e sua redefinição como uma fonte de puro prazer e gratificação (Jameson 2007).

Algumas das características identificadoras da cultura Pós-Moderna, na ótica de Jameson, ganhariam destaque em:

a) Uma nova falta de profundidade, delongada tanto para a teoria contemporânea quanto para a cultura da imagem vivenciada;

b) $\mathrm{O}$ enfraquecimento da historicidade, seja em nossas relações com a história pública, seja em nossas novas formas de temporalidade priva$\mathrm{da}$, de maneira que uma estrutura esquizofrênica (e lacaniana) passou a determinar "novos tipos de sin- 
taxe e de relação sintagmática nas formas mais temporais de representação" (Jameson 2007: 32) - daí uma circulação social e ênfase na cultura do simulacro;

c) Matiz emocional outro (no qual saem de cena, conforme observado anteriormente, as teorias mais antigas do sublime, em substituição por outras instantâneas e rapidamente perecíveis);

d) Uma profunda relação de todos os aspectos da vida social com a nova tecnologia, transformada em uma das protagonistas de um novo sistema econômico mundial;

e) O pastiche, ou a multiplicação e colagem sem relevo de estilos, paródia vazia sem senso de humor (Jameson 1993), o que passou a implicar no "desaparecimento do sujeito individual, ao lado de sua consequência formal, a crescente inviabilidade de um estilo pessoal" (Jameson 2007: 43);

f) A ausência de qualquer grande projeto coletivo, bem como o desmonte de conceitos Modernos como o de identidade, em virtude da experiência da perda do eu no tempo indiferenciado, e da proliferação de grupos sociais os quais passaram a falar línguas particulares (profissões desenvolvendo seus códigos ou termos privados, e os indivíduos tornando-se um exemplo de isolamento linguístico, separados de todos os outros).

Neste enredo, ainda que superficialmente fosse muito admissível ser guiado pelas observações do autor, muito se ressaltou sobre o quanto o mesmo apresentou uma dificuldade para mapear um espaço internacional de realidades históricas descontínuas, haja vista sua falta de preocupação para dar conta das passagens intersticiais e dos processos de diferenças culturais presentes nas categorias que fogem das nomenclaturas. Sua dificuldade de mobilização ante sua condição e situacionalidade ${ }^{6}$ parcial quando as "circunstâncias individuais são tão instáveis e sem identidade, que não podem servir como objeto de reflexão prolongada" (Rabinow 1999: 93), de certa forma, trouxeram alguns dos inúmeros diálogos contraproducentes ao seu corpo teórico.

É, ademais, pertinente problematizar o eixo espacial-visual das apreensões de Jameson (2007), uma vez que, dado o atual afastamento temporal nosso em relação às suas publicações, escutamos ruídos frequentes de como este autor parece ter sido levado principalmente por impressões menos avaliativas das culturas e das artes, derrogando a elas uma visão rasteira e unidimensional, sem substância, significado e nexo com o passado. De acordo com pontuado por Kellner (2001: 302), os textos aqui pensados de Fredric Jameson colocaram em xeque a continuidade da pertinência dos modelos de profundidade hermenêutica, como é o caso do "marxista, de essência e aparência, consciência verdadeira e falsa, ideologia e verdade; o freudiano, de significados latentes e manifestos; o existencialista, da existência autêntica e inautêntica; o semiótico, de significante e significado", modelos de profundidade estes 
que nos são continuamente reinscritos.

Contra algumas das expectativas de leituras efetuadas por Jameson e sua possível postura em favor de uma morte da hermenêutica, é constantemente debatido o quanto o autor não propiciou um acesso mais denso a uma análise interpretativa da imagem, da narrativa, das ideologias e dos significados, os quais continuam presentes na proposta de uma visão Pós-Moderna da cultura (Kellner 2001). Mais relacionado hoje a um cego envolvimento com as críticas do suposto apogeu do poderio neocolonialista cultural norte-americano (ou até do capitalismo como protagonista de tal papel), Fredric Jameson bloqueou, passionalmente, a possibilidade de aceite da tradução cultural como algo negociável e irregular para qualquer indivíduo encontrado na trama intersubjetiva e contemporânea.

O filósofo e sociólogo francês Jean Baudrillard é outro intelectual cuja obra também realizou um entrelaçamento entre os domínios econômicos ou produtivos e os domínios da ideologia ou da cultura e da imagem. Proximamente tributário de um revisionismo situacionista do mundo contemporâneo, este filósofo, sem embargo, se mostrou igualmente radical e irredutível quanto à sua interpretação Pós-Moderna das sociedades contemporâneas, se comparado com os posicionamentos de Fredric Jameson.

Para Jean Baudrillard (1990), o mundo contemporâneo passou a viver uma explosão e aceleração de suas mercadorias culturais e artísticas, de forma que as mesmas passaram a refletir o que ele chamou de operacionalização geral do significante: etapa de mercantilização de toda e qualquer engrenagem social constituinte. Seus escritos geralmente buscaram tratar de um momento em que "os artefatos culturais, as imagens, as representações e até os sentimentos e estruturas psíquicas tornaram-se parte do mundo contemporâneo" (Connor 2004: 48), de maneira a desencadear um estado alegórico de utopias realizadas, onde é preciso paradoxalmente continuar a viver (Baudrillard 1990).

Sob o vislumbre do que seria uma serialização de eventos e sentimentos cotidianos, o autor considerou que passamos a um contexto de hiper-realização de ideais e de experiências em uma simulação indefinida; viramos retro alimentadores de uma rede fadada à comutação incessante e, portanto, à indeterminação crescente e ao princípio de incerteza (Baudrillard 1990). Seus conceitos de simulacro e simulação ${ }^{7}$, dois sustentáculos ligados à maneira com a qual o indivíduo passou a perceber a realidade e a si mesmo, advieram na qualidade de efeitos máximos de coerência da classificação do valor - valor este agora fractal após passar pelas etapas do natural (valor de uso), do mercantil (valor de troca) e do estrutural (valor de signo) (Baudrillard 1994).

Assim como Jean-François Lyotard e Fredric Jameson, Jean Baudrillard pareceu seguir alguns rastros do que Hall (2003) chamou de centro da aspiração universalista e panóptica da globalização, drama mítico relacionado mais a uma experiência de fantasia do que com uma realidade de autorreconheci- 
mento; ambiguidade conceitual ao se estabelecer em um horizonte de quebra da metafísica Moderna e uma práxis da não problematização de suas próprias respostas generalizantes. Igual participante da crença de que os sujeitos Pós-Modernos haviam se perdido para sempre numa sucessão fragmentária de espelhos, jogo infinito de imagens supérfluas e sem significados (Kellner 2001), Baudrillard, mesmo estando no início de um debate acerca das novas condições contemporâneas das sociedades, não permitiu admitir uma nova agenda polissêmica para indivíduos e eventos culturais, inseridos em uma arte outra de governar e viver mundos.

No que concerne ao debate sobre as artes, mais especificamente, devemos ressaltar ainda como os autores deste percurso não se mostraram menos opinativos e conflitantes. Interessados na transformação cultural das sociedades ocidentais inclusive pelas artes plásticas, este grupo enxergava basicamente o aumento exponencial do consumo e produção de imagens globais como um indicativo possível de espetáculos vazios, promoção publicitária e integração artística à produção das mercadorias em geral (Jameson 2007; Harvey 2011).

Por vezes incertos quanto às rupturas com o Modernismo - seriam os tempos atuais uma quebra radical ou uma revolta no interior deste último? -, os diálogos Pós-Modernos para as artes visuais privilegiaram a aceitação do efêmero, do descontínuo, do fragmentário e do caótico, sem oporem-se a eles e sequer definir seus elementos recorrentes como fatores constituintes.
Como bem questionou David Harvey, Será o Pós-Modernismo um estilo, caso em que podemos razoavelmente apontar como seus precursores o dadaísmo, Nietzsche ou mesmo as Confissões de Santo Agostinho, no século IV, ou devemos vê-lo estritamente como um conceito periodizador (caso no qual debatemos se ele surgiu nos anos 1950, 1960 ou 1970)? Terá ele um potencial revolucionário em virtude de sua oposição a todas as formas de metanarrativa (incluindo o Marxismo, o Freudismo e todas as modalidades de razão iluminista) e de sua estreita atenção a "outros mundos" e "outras vozes" que há muito estavam silenciados (mulheres, gays, negros, povos colonizados com sua história própria)? Ou não passa da comercialização e da domesticação do Modernismo e de uma redução das aspirações já prejudicadas deste a um ecletismo de mercado "vale tudo", marcado pelo laissez-faire? (2011: 47).

De acordo com uma passagem detectada por Baudrillard (1990: 22), a qual acreditava que "por trás de todo o movimento convulsivo da arte contemporânea, haveria uma espécie de inércia, algo que não conseguiria superar-se $\mathrm{e}$ que giraria sobre si mesmo numa recorrência cada vez mais rápida", os diálogos Pós-Modernos sobre as artes trataram de não aspirar a nenhuma representação unificada do mundo, nem retratar este mundo como uma totalidade cheia de conexões e diferenciações. Para estes autores, as suas respostas para o universo impossibilitariam qualquer espécie de projeto global da diferença, ou mesmo um olhar macro 
para entender o estar-junto de populações cada vez mais interconectadas. Os pensadores deste grupo passaram a referendar, contraditoriamente, uma contínua caminhada rumo a um patamar pleno de diferenças serializadas e, logo, capazes de fundir um panorama cultural sobrepujado pelo mercado.

Fredric Jameson, por continuidade a este enredo de reflexões, via na obra Diamond Dust Shoes, de Andy Warhol (Figura 1), uma indicação ou sintoma de uma realidade mais vasta que se colocava como sua verdade última (Jameson 2007). Evidenciado o fato de que esta obra seria centrada em torno da mercantilização e do fetichismo exercido por mercadorias presentes massivamente no chamado capitalismo tardio, o crítico a via como evidência da mudança tanto no mundo dos objetos, transformados em um conjunto de textos ou de simulacros, quanto na disposição do sujeito, integrado num chamado esmaecimento do afeto. Embora não haja uma inverdade completa nas suas observações, sua leitura em torno de Warhol não valorizou o olhar do artista ao criar diferença crítica no comum, quando imagens e produtos serializados (neste contexto, potenciais exemplares de indiferença) também revelavam operações capitalistas irregulares de oferta e demanda, tantas delas baseadas no esmaecimento do afeto frente aos ciclos de informação.

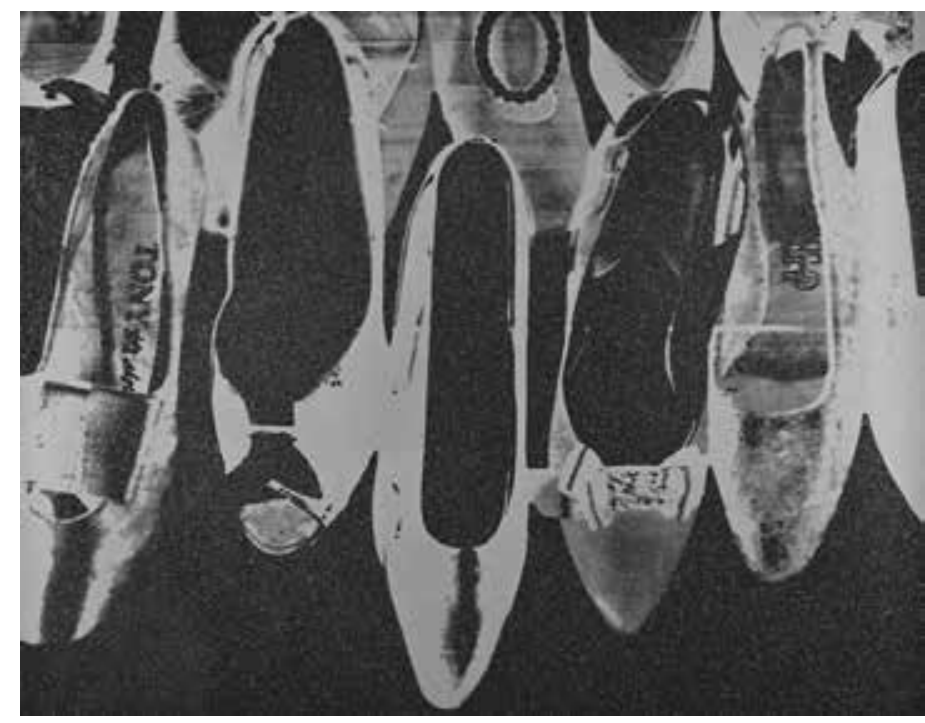

Figura 1. Diamond Dust Shoes, de Andy Warhol. Fonte: Jameson 2007.

Outro exemplo, desta vez apresentado por um dos continuístas dos debates Pós-Modernos, Steven Connor (2004), enxergava, dentre inúmeros outros exemplos, na fotografia Cowboy, de radical no estético e nas relações hu-
Richard Prince (Figura 2), alguns dos efeitos da Pós-Modernidade nas artes. Interessado em como o contemporâneo passou a gerar uma instabilidade 
manas, de maneira a visibilizar múltiplos direcionamentos, a fotografia em questão, uma apropriação então reprocessada pelo artista de uma imagem publicitária de um outdoor, revelava, para Connor, uma ampla rede de produções visuais empertigadas em um cosmopolitismo irônico e em uma ce- lebrada perda da noção de identidade e do valor da fotografia como documento - algo igualmente questionável, visto sabermos que a diferença, mais do que aproximar, passou a gerar também inúmeras outras fronteiras e reafirmações de pertença cultural.

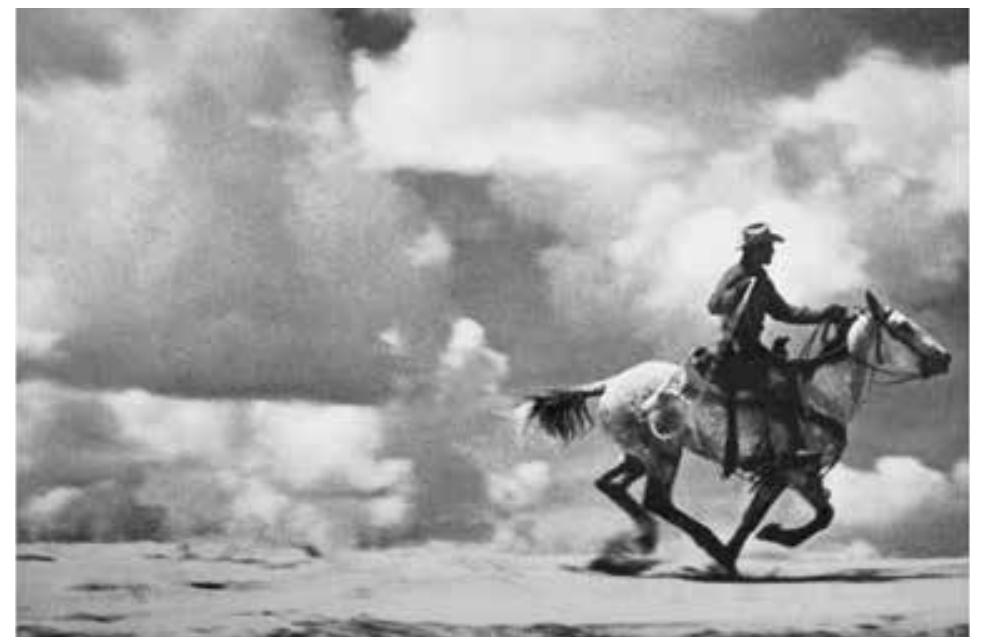

Figura 2. Cowboy, de Richard Prince. Fonte: Connor 2004.

Uma vez que a preocupação Pós-Moderna estava voltada para o significante, e não para os significados, com a participação, a performance e o happening apenas, em vez de um objeto de arte acabado e autoritário (Harvey 2011), os autores aqui apresentados puderam rejeitar a ideia de continuidade, abandonando o sentido de memória histórica de valores e crenças, e viram como a produção artística de nosso mundo mais conectado absorvia referências de tempos distintos e as classificava como aspectos do presente; buscava se conectar à noção de espetáculo apenas em termos de quão espetacular este poderia ser.
A maioria das imagens contemporâneas, vídeo, pintura, artes plásticas, audiovisual, imagens de síntese, é literalmente imagens em que não há nada para ser visto, imagens sem vestígios, sem sombra, sem consequências. $\mathrm{O}$ que se pressente é que, por trás de cada uma, algo desapareceu. Elas são apenas isto: o vestígio de algo que desapareceu (Baudrillard 1990: 24).

Uma grande controvérsia dos olhares Pós-Modernos para as artes foi a de fazer uso de exemplos geralmente dos grandes circuitos oficiais/ mercadológicos para transformá-los em regra. E seja por também não ultrapassar a área das superfícies semânticas destes 
exemplos para outras significativas, seja por imputar juízos de gosto não atentos aos modos de transformação das produções e recepções das artes, as colocações em foco trataram de aplainar todo um vasto terreno de produções distintas e nada conciliatórias: as experiências periféricas, as voltadas para circuitos undergrounds, discursivos e contra culturais, dispostos a problematizar e criticar os novos rumos das artes após uma imersão intensa em novas tecnologias; as de comunidades amplamente diferentes quanto à construção sensível, entre tantas outras subestimadas.

Corroborando mais uma vez com o preconizado por Kellner (2001), muitos dos discursos deste contexto erradicaram/ subestimaram a possibilidade polissêmica das artes contemporâneas e instituíram uma interpretação muito genérica para aqueles que foram catapultados, igualmente, por uma velocidade de experiência e respostas, muitas vezes incompatível com argumentações densas e capazes de decantar as inúmeras nuances dos nossos percursos culturais complexos. Ainda que uma série de dilemas levantados pelos autores associados a este contexto tenha se mantido inquietante, os limites deste pensamento se fizeram cada vez mais visíveis e necessitados de novas reinscrições.

\section{CONVERSA 2: O SISTEMA DE ARTE/ CULTURA PARA A ANTROPOLO- GIA PÓS-MODERNA}

$\mathrm{Na}$ esteira desses eventos desvelados pela emergência do paradigma Pós-
-Moderno na filosofia e na sociologia, encontramos novos ecos e reescrituras das fronteiras do pensamento ocidental a partir da chamada antropologia Pós-Moderna. E de certa forma, aqui retornamos a Clifford Geertz, ou melhor, aos pensamentos inscritos nas ampliações e problematizações de algumas das suas abordagens sociais, que tiveram o autor como principal cabeça de linhagem, como evidenciou Trajano Filho (1986).

O dito barulho ${ }^{8}$ emergente desta antropologia, principalmente aquele atrelado ao Seminário de Santa Fé e contemporâneo aos debates da filosofia e da sociologia, foram deveras conscientes da continuidade de suas discussões não como um passo a um evento simples e natural, sem maiores dissensões e conflitos internos e externos. Os tempos e as formas de apreender o mundo continuaram a mudar vertiginosamente, $\mathrm{e}$ esta revisão no núcleo do pensamento antropológico americano trouxe distintos rumos para aqueles momentos de incertezas, quando os discursos Modernos nas ciências humanas estavam sendo colocados à prova.

Para Luis Eduardo Soares (1988), por exemplo, estes tempos, para um entendimento mais didático, ainda que generalista, puderam ser divididos: 1) por uma facção interpretativa atuante, leitora de Heidegger à luz de Nietzsche, e que hesitava "entre o elogio do saber fragmentário correspondente a um real parcializado, que resiste às totalizações impostas pela unidade do conceito, e um 'neo-positivismo' crítico" (Soares1988: 102) - o que poderia ser atribuído às reflexões Pós-Moder- 
nas de Lyotard, Jameson e Baudrillard -; 2) e por outra porção científica interpretativa, ou de indivíduos ao menos afluentes a ela, a qual já retomava Heidegger submetido ao desafio do passado - porção encabeçada principalmente pela obra de Hans-Georg Gadamer, filósofo ao qual Geertz era deveras referente e, por extensão, vários dos antropólogos relacionados a ele, caso de muitos dos envolvidos no Seminário de Santa Fé.

Foi a partir deste segundo agrupamento (o interpretativista gadameriano), mais especificamente, que se esquadrinhou uma direção para a pesquisa antropológica que buscou "situar-se num horizonte marcado pelo primado da categoria relativizadora de pertencimento, pelo foco na diferença e no particular" (Soares, 1988: 102) - elementos os quais travaram uma autocrítica para o processo de produção de interpretações culturais e artísticas, e que deram espaço para uma maior discussão das narrativas totalizantes.

O já mencionado Seminário de Santa Fé marcou este período para a antropologia e gerou uma coletânea de ensaios chamada Writing Culture, cujo tema central girou em torno do escrever etnográfico. Então concebido como incentivador à experimentação da pesquisa antropológica e, "se por nada mais, por trazer uma consciência estética e ética para a antropologia e por advogar etnografias menos aborrecidas" (Trajano Filho 1986: 150), este seminário também ocasionou, como refinador de suas operações, a forma polifônica, advinda do Círculo Linguístico de Mikhail Bakhtin (Fischer
1986; Tedlock 1986; Crapanzano 1986; Clifford 1986; 1998) - aspecto, por conseguinte, em que se buscou melhor avaliar os contextos, os diálogos, as análises de peculiaridades e as relações intersubjetivas entre antropólogos e interlocutores como referenciais para uma pesquisa coerente ${ }^{10}$, feita em um mundo muito mais entremeado pelas reinscrições do que pelas semelhanças. Para muitos antropólogos os quais se voltaram a analisar este período de mudanças, os etnógrafos pós-modernos de Santa Fé estabeleceram um patamar de objetivação da desnorteante complexidade do mundo, pressuporam sua irredutibilidade e negaram a possibilidade de reconstruir uma totalidade que desse sentido a todas as posições diversas (Caldeira 1988). Inseridos numa nova tradição de questionar a produção verossímil de saberes, este grupo passou a fornecer, no mínimo, perguntas reverberantes para o novo trabalho da antropologia na virada do século XXI, inclusive para a antropologia voltada para aspectos visuais.

O debate sobre as artes, neste contexto, encontrou em um dos componentes do Seminário um de seus maiores leitores ${ }^{11}$. No ensaio On Collecting Art and Culture, de seu livro Predicament of Culture, James Clifford (1988) buscou desvelar outro caminho para a complexa relação entre os campos das culturas e das artes, geralmente superpostos, porém, na prática, separados por argumentos questionáveis. Neste ensaio, o intelectual principiou suas análises por uma negação inicial, ou uma oposição, entre os campos da arte e da cultura. Esta divisão em 
pares distintos geraria, consequentemente, quatro termos, estabelecidos em eixos horizontais e verticais, ou quatro zonas semânticas: (1) zona de autênticas obras de arte; (2) zona de autênticos artefatos; (3) zona de inautênticas obras de arte; (4) zona de inautênticos artefatos (Figura 3).

O SISTEMA DA ARTE-CULTURA

Uma Máquina de Fazer autenticidade

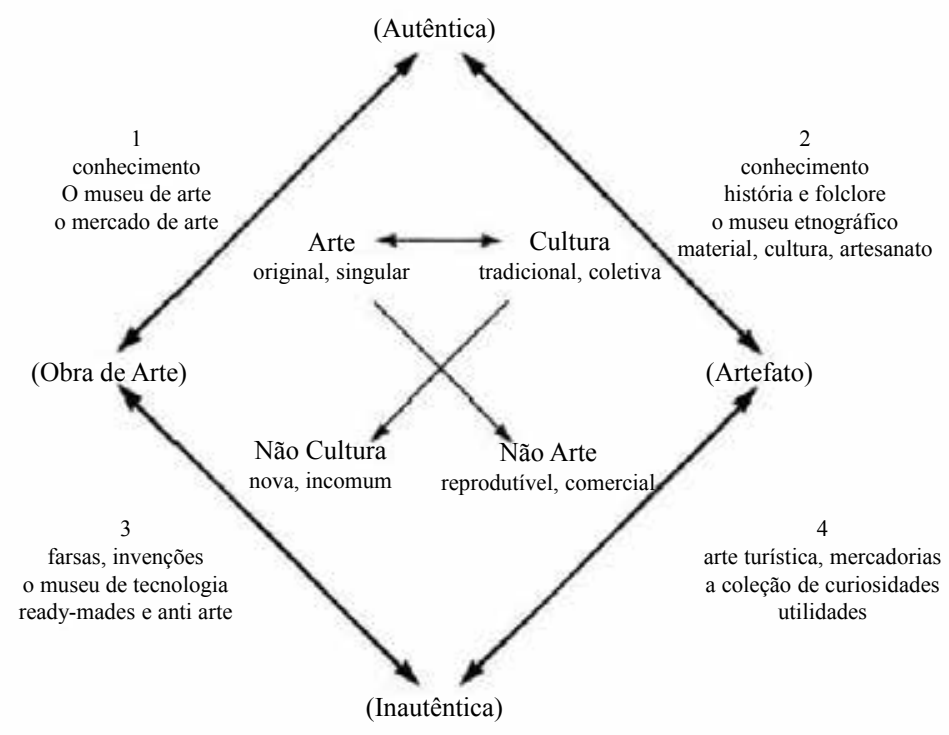

Figura 3. O Sistema da Arte-Cultura, de acordo com James Clifford (1988: 224).

De acordo com Clifford (1988), o próprio sistema social ocidental tratou de classificar os objetos e fenômenos artísticos entre os dois polos (artístico e cultural) e, a partir deles, ainda pôde subdividi-los de acordo com seus contextos positivos e negativos de circulação. Neste sentido, as movimentações de cunho positivo ocorreriam da base para o topo e da direita para a esquerda, sendo que estas movimentações selecionariam artefatos de grande valor ou raridade, valores estes garantidos por um status cultural em vias de desaparecimento ou pelos mecanismos de seleção e valoração estabelecidos pelo mercado das artes.
No caso mais específico das artes plásticas, o antropólogo insinuou que o reconhecimento artístico seria garantido por conhecedores ou colecionadores (e aqui ele não deu margens às problemáticas do próprio mercado já sobrepujar, inclusive, os olhares "especializados" e as antigas divisões binárias entre arte e cultura), e este reconhecimento se daria por princípios mais do que simplesmente estéticos, visto as definições de beleza e de interessante mudarem aceleradamente.

O caso de exemplos de artefatos históricos ou culturais que poderiam ser promovidos ao status de belas artes, visto serem casos especiais e selecio- 
nados de criação inventiva, seria visível na coleção de objetos tribais localizados em galerias de arte (por exemplo, os da Ala Rockefeller, no Museu Metropolitano de Nova York), nos mobiliários, maquinários e carros (ocorrência semelhante encontrada no Museu de Arte Moderna de Nova York), ou nos expostos em qualquer museu das grandes cidades do globo, de acordo com protocolos mais formalistas do que contextuais. Em todo caso, o diagrama de movimentações apresentado pelo autor, além de demonstrar um separatismo construído e, muitas vezes, contraditório entre as produções tidas por culturais das artísticas, por conseguinte, desvelou uma exclusão e marginalização de vários resíduos e contextos emergentes, bem como generalizou relações de interesse e negociação para a circulação de bens culturais e artísticos no sistema das artes.

Importantes para expandir a agenda artística de museus e espaços de entendimento do outro, os processos artísticos indeferidos pelo circuito das artes, na concepção do autor, demonstravam um limitante conceitual para as próprias ficcionais fronteiras dos regimes visuais (Clifford 1988). Muito embora Clifford não tenha escrito seu texto após dialogar com o grande impacto do que se convencionou chamar de arte no campo expandido - um tipo de entendimento no qual as fronteiras entre campos e objetos culturais já não se mostra mais tão bem separada como outrora -, suas análises deram continuidade a um debate no entrecampo arte e antropologia (ver Fletcher et al. 2014), a fim de entender a importân- cia e a complexidade de uma produção humana alocada nos territórios da criatividade plástica.

Devemos acrescentar, portanto, que foi em meio aos debates e constantes contra-argumentações desta geração de antropólogos, que se iniciaram alguns procedimentos diferenciados de narrativas sobre os outros e sobre os tipos de críticas, de políticas efetuadas e de formas de enxergar a diversidade em aspectos culturais, artísticos, etc. (Carvalho 2001). Favoráveis por trazer uma maior flexibilidade ao exercício antropológico (ver também Caldeira 1988; Rabinow 1999), ainda que não plenamente atentos às relações de interdependência entre as sociedades mesmo na diferença (interdependência esta que somente a história subsequente ratificaria e problematizaria), este grupo de intelectuais erigiu, no interior de suas próprias instituições "centrais", algumas das fendas para a inserção, nestes mesmos centros hegemônicos, de uma presença epistemológica, constituída por pesquisadores advindos de localidades antes silenciadas.

Intencional ou não, este grupo interpretativista Pós-Moderno proveu uma parcela de precedência para se pensar, a partir de uma geografia científica mais complexa, os rastros do ingovernável e da experiência caótica das emergências concorrentes, dialógicas e, nem sempre, pacíficas no mundo contemporâneo. Não se pode mensurar o intuito de suas ações problematizantes; entretanto, o mundo das ciências sociais se viu mais aberto, também em função de suas posturas antropológicas, para novas agendas científicas e olhares que 
tentassem relativizar um mundo emergencialmente diverso.

\section{CONVERSA 3: A ARTE PARA ALÉM DOS ÚLTIMOS LIMITES}

$\mathrm{Na}$ continuidade do rastro teórico e polifônico erigido após o término da Segunda Guerra e após a falência de pelo menos parte das noções Modernas nas ciências sociais, novas agendas interpretativas para o mundo das culturas e das artes se fizeram presentes e possibilitaram um olhar etnográfico continuamente descentrado. Dessa forma, diversos debates acadêmicos e politizantes questionaram as referências canônicas, de maneira que deixaram de considerar estas referências como as decisivas para o pensamento intelectual social das periferias globais (uma forma de buscar, nas margens, a transformação do cânone e a relocação da cultura como estratégia transnacional e de tradução) (Bhabha 2003b; Ribeiro 2006).

Sob esse aspecto, e observado o fato de tantos viverem em localizações situadas fora dos holofotes da produção teórica, social e artística (sujeitos vários, mas que, ironicamente, tentavam responder às suas emergências a partir de um pensamento criado para uma realidade empírica que não lhes cabia completamente), reiterou-se os enunciados Pós-Colonial e Decolonial para propor uma opção de deserção do excesso de narrativas do centro (Mignolo 2010) e de implementação de uma nova agenda etnográfica para recuperar explicitamente sua crítica à nossa posição de periferia do Ocidente (Car- valho 2001).

Diferente de inúmeras abordagens conceituais em voga na atualidade, haja vista uma recusa de "conceber o conhecimento como diletantismo ou fazer dele um exercício de proselitismo" (Schmidt 2011: 27), os posicionamentos subalternos ${ }^{12}$ (termo assumido, embora não perenemente, pelos pós-coloniais e decoloniais) não precisaram ser lidos como rendições ao ceticismo radical de algumas disposições teóricas do Pós-Modernismo e do Pós-Estruturalismo, muito menos como uma mera analogia de relativismo radical. Embora pensadores do Decolonialismo tenham observado que as teorias Pós-Coloniais têm seu lócus de enunciação nas heranças coloniais do Império Britânico, o que portanto não promoveria uma ruptura adequada com autores eurocêntricos (Mignolo 1998), ambos casos de escritas mais inclusivas e menos autoritárias dos pensamentos aqui em questão buscaram questionar epistemologias para valorizar e descobrir outras racionalidades e perspectivas pluriversais para as artes e para as ciências sociais (Ribeiro 2006; Barriendos 2008; Ballestrin 2013).

O debate destes grupos em torno das artes visuais tem canalizado grande energia para reescrever acontecimentos artísticos não agenciados por uma história até mesmo recente. Com o intuito de propor uma melhor reflexão sobre experiências visuais feitas a partir de relações contextuais distintas e que não poderiam ser encerradas de acordo com protocolos do centro, inúmeros autores do debate Decolonial, por conseguinte, tem reafirmado uma 
nova agenda interpretativa e destituída dos processos de colonização do poder, do ser, do ouvir, do fazer e do ver.

"Siguiendo la propuesta del teórico peruano Aníbal Quijano, apuntamos la necesidad de construir un nuevo acuerdo visual transcultural al cual se podría definir como un diálogo inter-epistémico entre los regímenes visuales canonizados por la modernidade eurocéntrica y aquellas culturas visuales otras que han sido racializadas y jerarquizadas por el proyecto de la Modernidad/ Colonialidad" (Barriendos 2008: 03).

Nesta esteira da chamada colonialidade do ver, podemos ressaltar o quanto determinados aspectos constitutivos deste regime geoepistemológico fizeram revelar uma forte conexão com as cartografias imperiais, com a proto-etnografia eurocentrada e a mercantilização atlântica da alteridade. Neste sentido, e pensando a partir de como a conquista das Américas e a redefinição deste novo outro etnográfico passou por um disciplinamento material, teológico e ontológico, não podemos deixar de mencionar a bula Inter-Caetera, de 1493, a qual amparou a reinvenção das justificativas medievais em torno da exploração da força de trabalho indígena e do consumo de metais preciosos, uma construção, para o colonizador, de um "fora" etno-cartográfico necessitado de uma colonialização simbólica e visual (Barriendos 2008).

A matriz discriminatória da alteridade das populações indígenas nas Américas consistia em uma racionalização destas populações como apolíticas ou fora das leis dos homens e das leis di- vinas. Nesse sentido, a colonialidade do ver se converteu em uma potente maquinaria epistêmico-racial baseada não somente na negação ontológica da humanidade indígena, como também na inferiorização corpo-política e na racialização etno-cartográfica da América Latina.

Observada a sobrevivência ainda hoje de uma chamada cromática do poder ${ }^{13}$, a qual se utilizou, desde os primeiros efeitos da colonização, de um sistema dinâmico e sofisticado de exclusão e obediência, capaz de converter a diversidade cromática e visual de sociedades não hegemônicas em uma narrativa reducionista e falsa de uma universalidade da arte (Albán 2011), a proposta latino-americana de problematização desses antigos limites das interpretações e fruições simbólico-visuais tratou de apontar, inclusive, como mesmo as chamadas vanguardas artísticas foram tentativas de implementação, em outros territórios cosmológicos, de um papel subsidiário de tendências, discursos e re-produções dos eixos europeus e norte-americanos. Em consequência, a colonialidade do ver se manteve indissociável até nas recentes tensões geopolíticas e nas dívidas econômico-culturais da região eurolatinoamericana, isto é, nas consequências birregionais do capitalismo cultural transatlântico no contexto da economia global (Barriendos 2008).

Com uma potência erradicadora de muitos dos agentes e processos artísticos locais por meio de uma imposta auto-reflexividade da arte - auto-reflexividade na qual o outro foi exotizado e funcionalizado a partir de um projeto 
hegemônico -, a chamada pretensão de segurança fincada no poder da razão e da progressão se tornou a face mais escura de uma construção cultural teleológica a abarcar mesmo o território das artes visuais, de maneira que esta dimensão docilizante de sujeitos submetidos a processos contínuos de exclusão e de desigualdade se tornou um dos fundamentos para toda uma sorte de colonização da cotidianidade do sujeito, a ponto de pavimentar um nível de estabilidade almejada em diversas ordem de existência: afetiva, econômica, trabalhista, social e emocional (Quijano 1992).

Com o intuito de não encarcerar manifestações de comunidade étnicas e suas relacionais experiências artísticas em folclorizações reducionistas, ou mesmo de tratar uma diversidade de pensamentos, opções de vida, maneiras diferentes de fazer, sentir e pensar arte sob uma leitura estética canônica, portanto, não agenciada, os pensamentos desenvolvidos a partir das agendas Pós-Coloniais e Decoloniais buscaram (assim como continuamente buscam) (re)trazer visibilidade e dignidade a outros tipos de produção material e simbólica, inclusive àquelas não encontradas nos circuitos institucionalizados da arte, mas fundamentais para se exercer um papel de resistência sociopolítica ao que fomos, ao que somos e ao que queremos ser.

"El arte como acto de reflexión permanente $-\mathrm{y}$ no solamente como el hecho de realizar objetos artísticos - debe contribuir a ensanchar los escenarios de discusión en torno a la exclusión social, la racia- lización, la violencia genocida, la reafirmación de los estereotipos y el autoritarismo. De lo contrario - y quizá sea válido también - el arte se convierte en un ejercicio narcisista que nos lleva a producir objetos para la auto-satisfación del campo, del arte y todas las contigencias que lo acompañan" (Barriendos 2008: $06)$.

Por vezes protagonistas em antecipar e inspirar debates sociais (Hissa 2013), o universo das artes visuais em seus circuitos local, nacional e internacional (e aqui podemos incluir toda a forma de mercado e agenciamento de galeristas, bem como a participação de indivíduos do centro e dos diversos tipos de margens em circuitos formais, comerciais, experimentais e undergrounds), para além de indicar uma perda da autoridade destas consigo mesmas (García-Canclini 2012), puderam ser tidas como a concretização de "suas articulações em relações de alteridade, com aparecimentos surpreendentes em sistemas de significados, formas e valores diferentes dos seus próprios" (Bhabha 2012: 23). Em outras palavras, são estas produções artísticas possíveis de serem tomadas como células portadoras de discursos geradores de reposicionamentos sígnicos e também de reposicionar olhares significantes de acordo com a ótica e o contexto de suas fruições.

Uma obra de arte (...) vive no 'limite' da existência. Sua temporalidade é contingente e contextual; é iminentemente aberta a leituras revisionistas e resistentes, traduções culturais imprevistas, ou ressignificações formais e ideológicas no processo de apropriação política 
ou institucional - ou, como disse o artista, deve estar sujeita a mudança sem aviso prévio (Bhabha 2012: 22).

Em um estado potencial de acesso social cada vez mais amplo, acesso este que tira as artes dos seus antigos lugares sacralizados pelo simples fato das mesmas, ou melhor, um acesso a parte delas se encontrar disponível na rede para reconhecimento ${ }^{14}$, as artes visuais atuais - e incluem-se neste aspecto as poéticas desenvolvidas com as condições que lhes são possíveis (e muitas vezes, não ideais) - são potenciais para deflagrar uma pedagogia incidente e diálogos politizados e politizantes para os diversos grupos sociais e para as formas como estes grupos podem pensar regimes de visualidade próprios (Lucero 2011).

É neste sentido, segundo Barriendos (2008), que o reconhecimento da colonialidade do ver pode nos conduzir a paradigmas escópicos adjacentes, alternativos e contestatários, inscritos no desenvolvimento histórico da modernidade colonial. Ou, em resumo, derramar outras luzes sobre o próprio poder etnófago da imagem eurocêntrica, de maneira a propor uma superação do ocularcentrismo $^{15}$ antropológico tão entranhado nas sociedades das Américas Latinas, das Áfricas, das Ásias, das Amazônias, dentre outras localidades, mediante um olhar pluriversal e inclusivo.

\section{ALGUMAS CONSIDERAÇÕES}

Desde os estilhaços narrativos e os estranhamentos conceituais desvela- dos a partir do pós-guerra, o mundo contemporâneo, com suas sociedades complexas e intermitentemente colaborativas, se viu diferente. Quando pensamos hoje em alternativas de entender as mudanças nos diversos estatutos do interpretar culturas e regimes visuais, vemos um emaranhado de discursos e práticas permeado por alianças, dissidências e contrarrespostas.

Se de um lado conseguimos ler ruídos já nas inscrições desveladas por Clifford Geertz, ou mesmo pelos diversos cientistas tributários ao seu interpretativismo cultural, de outro encontramos uma geração da filosofia, da sociologia e da antropologia Pós-Modernas, mesmo em seus passos iniciais, a perceber os efeitos contraditórios e nada celebratórios de uma nova dimensão intercultural das nações. Em todo caso, por um efeito pertinente, mas não ausente de constantes problematizações, o horizonte no qual o mundo das humanidades passou a se ver tratou de abrir fendas para que minorias reclamassem para si o papel de entender e ler suas próprias diferenças a partir de instrumentos conceituais cada vez mais próprios, ausentes do excesso de análises interpretativas do centro - algo, atualmente, vislumbrado nas novas geografias de saber das Ásias, das Américas Latinas, das Áfricas, do Oriente Médio, dentre outros, bem como através de cientistas diaspóricos atuantes numa linhagem de pensamento crítico e pluriversal.

No que concerne ao debate das ciências sociais em torno do território das artes visuais, muito tem se problematizado acerca da chamada colonialidade 
do ver, sobrevivência de características, muitas vezes, predatórias, para se pensar e continuar regimes visuais em países das periferias globais. Em todo caso, seja pelo produtivo campo de repensar, sob novos termos, as negociações, nem sempre pacíficas, e as produções em artes visuais, seja por iluminar agendas críticas e contestatárias, os debates em torno da colonialidade do ver puderam e podem apresentar horizontes distintos para se entender as dimensões plásticas e culturais dos outros, não mais encerrando-os de acordo com protocolos não agenciáveis.

No fim das contas, para além de nossas ações (e isso é muito mais complicado de ser subjugado pelas garras da política perversa e do pensamento simplificante), o maior combustível para esse constante mover-se entre ruídos e silêncios vem de um termo já utilizado por Mauss (1972), que é o de solidariedade, ação entre sujeitos amparada pela crença que ultrapassa até mesmo nossos comportamentos culturalmente formatados. Muito apropriadamente, é esta intenção de solidariedade, um colocar-se no futuro como questão aberta, autocrítica e consciente de nossos limites e os dos outros, que nos fazem apostar em não podermos mais encontrar uma resposta final (pois sua pergunta já não estará mais lá), mas fortalecermos um debate para, continuamente, aproximarmonos de novos limites, em prol de uma civilização da diversidade, uma ética da frugalidade e uma cultura de baixa entropia.

\section{AGRADECIMENTOS}

Uma primeira versão deste trabalho foi apresentada no I Encontro de Antropologia Visual da América Amazônica, realizado em novembro de 2014, na cidade de Belém/PA. Os autores agradecem à CAPES, pela concessão de bolsa de Doutorado, e ao pesquisador Dr. Adolfo Albán Achinte (Universidad de Cauca, Popayán, Colômbia), pelas preciosas contribuições.

\section{NOTAS}

1 Partimos da ideia de contemporâneo como um campo de disputas pelo reconhecimento sociocultural, pelas autoafirmações étnicas e indenitárias e pelo questionamento da concepção das histórias e dos dispositivos os quais construíram narrativas excludentes ou silenciadas (Albán 2011).

2 A polifonia, um conceito estabelecido por Mikhail Bakhtin (2003), reconhece o diálogo e a criação artística como o encontro de diversas vozes, realidades e temporalidades, interceptando-se em um ir e vir sem categorização.

3 Este movimento tratou de problematizar as chamadas narrativas de países hegemônicos e colonialistas, os quais silenciaram e excluíram povos e cosmologias de seus lugares de enunciação. Os debates em torno do Pós-Colonial possuem algumas de suas primeiras considerações nos escritos do psicólogo martinicano Frantz Fanon, na década de 1950; nos do crítico literário Edward Said, na década de 1990; e no papel atuante de intelectuais das chamadas periferias globais em universidades europeias e americanas, na década de 1980 e 1990, com os nomes 
de Stuart Hall, Mary Louise Pratt, Homi Bhabha, Gayatri Spivak, entre outros.

${ }^{4}$ Decolonial é um movimento mental e epistemológico de crítica e rompimento com ordens coloniais, concepções de vida eurocêntricas e discursos de modernidade os quais excluíram grupos sociais indígenas e africanos na América (Sarraf 2013). Algumas das insinuações para esta problemática da colonialidade do ver e do ser na América Latina já apareceram, mesmo sem uma organização ainda demarcada, por volta dos anos 1970 nos escritos do antropólogo Darcy Ribeiro; nos debates iniciados pela teoria da dependência, com Aníbal Quijano; na filosofia e sociologia de Enrique Dussel e Orlando Fals Borda; através dos debates de Robert Ricard; e, alguns anos mais tarde, pela teoria da colonização do imaginário de Serge Gruzinski (Mignolo 2010).

${ }^{5}$ É importante observar que a Modernidade, conforme pontuado por Walter Mignolo (2010), trazia seu outro sinônimo, a Colonialidade. Esta faceta colonial da Modernidade implicava em maneiras impostas de poder, de ser, de ouvir, de fazer e de ver, conforme interesses dos centros Europeus e Norte Americanos.

${ }^{6}$ Rabinow (1999) alude à aproximação de Fredric Jameson com o trabalho dos situacionistas, grupo de críticos sociais radicais, cujas escrituras ganharam ressonância na França dos anos 1960. Para este grupo, a vida contemporânea fora aplainada por uma sociedade do espetáculo, na qual a imagem valia mais que o produto em si.

7 A simulação constitui o grupo dos objetos e experiências manufaturados e voltados para representar a realidade além de suas circunscrições - o que incorre em um evento hiper-real - e simulacro um estado de dormência dos sentidos para se perceber as reais fronteiras dos limites apagados pelo efeito da simulação (Baudrillard, 1994).

${ }^{8}$ Utilizamos o termo barulho para evidenciar um número de vozes que cresceu vertiginosamente no período do pós-guerra, cujas fontes, ironicamente, beberam também em alguns dos mesmos nomes da condição Pós-Moderna, vendo-se resultantes de tempos assombrados por tradições em migalhas.

${ }^{9}$ O Seminário de Santa Fé ocorreu na Escola de Investigação Americana de Santa Fé, Nuevo México, em 1984, e teve seu tema central em torno da redação do texto antropológico, da autoridade etnográfica e da relação entre pesquisador e seus pesquisados (Rocha \& Eckert 1998).

${ }^{10}$ Como observou James Clifford (1998: 58), uma pesquisa coerente "pressupõe um modo controlador de autoridade".

${ }^{11}$ Destaque também para George Marcus (2004), pois viu nas artes e, mais especificamente, na prática da performance uma aliança potencial para o campo da antropologia, uma vez que este diálogo não somente criticaria a antropologia por um suposto não-esteticismo interior ao seu campo, como a chamaria para um exceder antigas representações tradicionais e funções documentais.

${ }^{12} \mathrm{O}$ termo subalterno foi tomado emprestado de Antonio Gramsci, uma vez que este pontua as classes ou grupos desagregados e episódicos os quais possuem uma tendência histórica a uma unificação sempre provisória pela obliteração das classes dominantes (Ballestrin 2013).

${ }^{13}$ Esta categoria desvelou um sistema de representação baseado no entendimento e no pincel do colono do que seria arte, de forma a impedir representações outras dos povos colonizados (Albán 2011).

14 Os downloads e reproduções aqui mencionados não são comparáveis às 
obras originais, visto a fotografia ser o vetor de "uma identificação renovada entre a imagem como operação da arte e a imagem como produção de uma representação" (Rancière 2012: 105), mas, mesmo assim, propiciam maneiras alternativas de se relacionar com o ver sob o impacto dos meios eletrônicos (Machado 2010; Benjamin 2011b; Harvey 2011).

${ }^{15} \mathrm{O}$ termo ocularcentrismo problematiza os deslocamentos e críticas interpretativas ainda feitas a partir da percepção cultural do etnógrafo, mais do que do etnografado (Barriendos 2008).

\section{REFERÊNCIAS}

Albán, A. 2007. Arte, docencia e investigación. Revista de la Facultad de Comunicación Social y Publicidad de la Universidad de Santiago de Cali 5: 11-27.

2008. El acto creador como pedagogía crítica decolonial, in Cuentan las Culturas, los Objetos Dicen... Los mundos de Pajcha. Organizado por L. M. Z. Fontán; Z. Palermo; D. M. O. Coll, pp. 11-14. Salta, Argentina: Museo de Arte Étnico Americano, Ediciones Fundación Pajcha.

—. 2011. Estéticas decoloniales y de re-existencia: entre memorias y cosmovisiones, in La Arquitectura del Sentido II: La Producción y Reproducción en las Prácticas Semiótico-Discursivas. Organizado por J. Haidar \& G. S. Guevara, pp. 87117. Coyoacán, México: Escuela Nacional de Antropología y Historia, Instituto Nacional de Antropología y Historia, Consejo Nacional para la Cultura y las Artes, Programa del Mejoramiento del Profesorado - PromeP.

Bakhtin, M. 2003. Estética da Criação Verbal. São Paulo: Martins Fontes.
Ballestrin, L. 2013. América Latina e o giro colonial. Revista Brasileira de Ciência Política 11: 89-117.

Barriendos, J. 2008. Apetitos extremos: La colonialidad del ver y las imágenes-archivo sobre el canibalismo de Indias. Transversal, Multilingual Webjournal, Viena, EIPCP European Institute for Progressive Cultural Policies: 01-20.

Baudrillard, J. 1990. A transparência do mal: Ensaio sobre os fenômenos extremos. Campinas: Papirus. 1994. Simulacra and Simulation. Michigan: Michigan Press.

Benjamin, W. 2011. O narrador: Considerações sobre a obra de Nikolai Leskov, in Magia e técnica, arte e política: Ensaios sobre literatura e história da cultura, pp. 197-221. São Paulo: Brasiliense.

Bhabha, H. K. 2003a. Como o novo entra no mundo: O espaço pós-moderno, os tempos pós-coloniais e as provações da tradução cultural, in $O$ local da cultura. Organizado por H. K. Bhabha, pp. 292-325. Belo Horizonte: UFMG.

. 2003b. O Pós-Colonial e o Pós-Moderno: a questão da agência, in $O$ local da cultura. Organizado por H. K. Bhabha, pp. 239-273. Belo Horizonte: UFMG.

. 2012. Arte e Iminência, in Catálogo da $30^{\circ}$ Bienal de São Paulo: A Iminência das Poéticas, pp. 20-25. São Paulo: Fundação Bienal de São Paulo.

Caldeira, T. P. R. 1988. A presença do autor e a Pós-Modernidade na Antropologia. Novos Estudos CEBRAP 21: 133-157.

Carvalho, J. J. 2001. O olhar etnográfico e a voz subalterna. Horizontes Antropológicos 7(15): 107-147.

Clifford, J. 1986. On ethnographic allegory, in Writing Culture: the poetics and politics of ethnography. Organizado por J. Clifford 
\& G. E. Marcus, pp. 98-121. Berkeley; Los Angeles, California: University of California Press.

1988. On collecting art and culture,

in The Predicament of Culture: twentieth-century ethnography, literature and art. Organizado por J. Clifford, pp. 215-251. Cambridge/ Massachussets/ London: Harvard University Press.

1998. Sobre a autoridade etnográfica, in $A$ experiência etnográfica: antropologia e literatura no século XX. Organizado por J. R. S. Gonçalves, pp. 1762. Rio de Janeiro: UFRJ.

Connor, S. 2004. Cultura Pós-Moderna: Introdução às teorias do contemporâneo. São Paulo: Loyola.

Crapanzano, V. 1986. Hermes' dilemma: The masking of subversion in ethnographic description, in Writing Culture: the poetics and politics of ethnography. Organizado por J. Clifford \& G. E. Marcus, pp. 5176. Berkeley; Los Angeles, California: University of California Press.

Fischer, M. 1986. Ethnicity and the post-modern arts of memory, in Writing Culture: the poetics and politics of ethnography. Organizado por J. Clifford \& G. E. Marcus, pp. 194-233. Berkeley; Los Angeles, California: University of California Press.

Fletcher, J.; A. Sarraf \& E. Chaves. 2014. Conversações entre artes \& culturas a partir de olhares antropológicos. Iluminuras 15: 11-43.

Gagnebin, J. M. 2001. Memória, história, testemunho, in Memória e (Res)sentimento: indagacõos sobre uma questão sensivel. Organizado por S. Bresciani \& M. Naxara, pp. 85-94. Campinas: Unicamp.

García Canclini, N. 2012. A Sociedade sem Relato: antropologia e estética da iminência. São Paulo: Edusp.
Geertz, C. 2008a. A arte como um sistema cultural, in O Saber Local: novos ensaios em antropologia interpretativa. Organizado por C. Geertz, pp. 142-181. Petrópolis: Vozes.

2008b. Como pensamos hoje: a caminho de uma etnografia do pensamento moderno, in O Saber Local: novos ensaios em antropologia interpretativa. Organizado por C. Geertz, pp. 220-245. Petrópolis: Vozes.

Hall, S. 2003. A questão multicultural, in Da Diáspora: identidades e mediações culturais. Organizado por L. Sovik, pp. 49-94. Belo Horizonte: UFMG.

2009. A modernidade e os seus outros: três "momentos" na história das artes na diáspora negra do pós-guerra. $A r$ tafrica 1-26.

Harvey, D. 2011. A condição Pós-Moderna: Uma pesquisa sobre as origens da mudança cultural. São Paulo: Loyola.

Hissa, C. E. V. 2013. Entrenotas: compreensões de pesquisa. Belo Horizonte: UFMG.

Jameson, F. 1993. Pós-modernismo e a sociedade de consumo, in O mal-estar do pós-modernismo: teorias e práticas. Organizado por E. A. Kaplan, pp. 25-44. Rio de Janeiro: Jorge Zahar. 2007. Pós-Modernismo: a lógica cultural do capitalismo tardio. São Paulo: Ática.

Kellner, D. 2001. A Cultura da Mídia: Identidade e Política entre o Moderno e o Pós-Moderno. São Paulo: EDUSC.

Lucero, M. E. 2011. Decoloniality in Latin American Art. Southern Perspectives. Disponível em < http://www.southernperspectives.net $/ \mathrm{tag} /$ modernism $>$. Acessado em 10 jul. 2014.

Lyotard, J. F. 2009. A Condição Pós-Moderna. Rio de Janeiro: José Olympio.

Marcus, G. E. 2004. O intercâmbio entre Arte e Antropologia: Como a Pesquisa de Campo em Artes Cênicas pode Informar 
a Reinvenção da Pesquisa de Campo em Antropologia. Revista de Antropologia, São Paulo, v. 47, n. 01: 133-158.

Mauss, M. 1974. Sociologia e Antropologia. São Paulo: Edusp.

Mignolo, W. 1998. Posoccidentalismo: El Argumento desde América Latina, in Teorias sin Disciplina: Latinoamericanismo, Postcolonialidad y Globalización em Debate. Editado por S. Castro-Gómez \& E. Mendieta, pp. 31-58 México: Miguel Ángel Porrúa.

2010. Desobediencia

Epistémica: Retórica de La Modernidad, Lógica de La Colonialidad y Gramática de La Descolonialidad. Buenos Aires: Del Signo.

Quijano, A. 1992. Colonialidad y Modernidad-Racionalidad, in Los Conquistados: 1942 y la Población Indígena de las Américas. Editado por H. Bonilla, pp. 437-447. Ecuador: Libri Mundi.

Rabinow. P. 1999. Representações São Fatos Sociais: Modernidade e Pós-Modernidade na Antropologia, in Antropologia da razão. Organizado por P. Rabinow, pp. 71-108. Rio de Janeiro: Relume Dumará.

Rancière, J. 2012. O Espectador Emancipado. São Paulo: WMF Martins Fontes.

Ribeiro, G. L. 2006. Antropologias Mundiais: Para um Novo Cenário Global na Antropologia. Revista Brasileira de Ciências Sociais 60 (21): 147- 185.

Rocha, A. L. C.; Eckert, C. 1998. A Interioridade da Experiência Profissional do Antropólogo como Condição da Produção Etnográfica. Antropologia 2 (41): 107-136.

Said, E. 1994. Culture and Imperialism. New York: Vintage.

Sarlo, B. 2000. Cenas da Vida Pós-Moderna: Intelectuais, Arte e Vídeo-Cultura na Argentina. São Paulo: Editora UFRJ.
Sarraf, A. 2013. Religiosidade Afroindígena e Natureza Na Amazônia. Horizonte, Revista de Estudos de Teologia e Ciências da Religião 11: 476-508.

Schmidt, R. T. 2011. Pensamento-compromisso de Homi Bhabha: Notas para uma Introdução, in O Bazar Global e o Clube dos Cavalheiros Ingleses: Textos Seletos de Homi Bhabha. Organizado por E. F. Coutinho, pp. 13-61. Rio de Janeiro: Rocco.

Seligmann-Silva, M. 2006. Reflexões sobre a Memória, a História e o Esquecimento, in História, Memória, Literatura: o Testemunho na Era das Catástrofes. Organizado por M. Seligmann-Silva, pp. 59-85. Campinas: Unicamp.

Soares, L. E. 1988. Hermenêutica e Ciências Humanas. Estudos Históricos 1: 100-142. Tedlock, D. 1986. A Tradição Analógica e o Surgimento de uma Antropologia Dialógica. Anuário Antropológico 85: 183-202.

Trajano Filho, W. 1986. Que Barulho é esse, o dos Pós-Modernos? Anuário Antropológico 86:133-152.

Recebido em 06/01/2015

Aprovado em 15/08/2015 